\title{
Epidemiological pattern of leprosy in an endemic area of North-East Brazil, 1996-2005: the supporting role of a Nongovernmental Organization
}

\author{
0 perfil da hanseníase em uma área endêmica do nordeste do Brasil, 1996-2005: \\ atividade de suporte de uma Organização Não Governamental
}

\author{
Giuseppe Mastrangelo ${ }^{1}$, Luca Scoizzato ${ }^{1}$, Emanuela Fadda ${ }^{1}$, Gilberto Valentim da Silva ${ }^{2}$, \\ Luimar De Jesus Santos ${ }^{3}$ and Luca Cegolon ${ }^{1}$
}

\begin{abstract}
In an endemic area of North-East Brazil (the town of Picos, State of Piauí), a nongovernmental organization (NG0) supported the activity against leprosy in connection with governmental health organizations and local agents. The indicators of leprosy elimination were compared over time (within Picos) and across space (Picos versus Piauí). The case detection rate, above 8 per 10,000 people in the last two years of observation, increased over time in Picos $(\mathrm{p}=0.010)$. This finding could be due to active detection activities rather than expanding endemicity, as suggested by the reduction in leprosy in children $(\mathrm{p}=0.053)$ and the decrease in the proportion of new cases with grade 2 disability $(\mathrm{p}<0.001)$. These indicators showed a more favorable time trend in the city than in the State, suggesting that NGO activity was supportive in the battle towards leprosy control.
\end{abstract}

Key-words: Leprosy. Leprosy elimination indicators. Case detection rate. Prevalence. Proportion of multibacillary patients.

\begin{abstract}
RESUMO
Para avaliar a atividade da sustentação fornecida por Organizações Não Governamentais (ONG)na luta contra a hanseníase, o perfil epidemiológico da doença em uma cidade é comparado ao perfil do todo Estado do Piauí. A tendência temporal da taxa de detecção é de aumento em Picos (p=0,010), e nos últimos dois anos de observação estava acima de 8 para 10.000 habitantes, duas vezes maior do que o limiar de hiperendemicidade (4 para 10.000). Como varia paralelamente com a redução da hanseníase nas crianças $(\mathrm{p}=0,053)$ e a diminuição da proporção de casos novos com grau 2 de incapacidade $(\mathrm{p}<0.001)$, o incremento no tempo da taxa de deteç̧ão pode ser atribuído mais à maior intensidade da atividade de detecção do que à expansão da endemicidade. Os indicadores de eliminação da hanseníase têm uma tendência no tempo mais favorável na cidade do que no Estado do Piauí, sugerindo que o ONG fosse útil na batalha para o controle da hanseníase.
\end{abstract}

Palavras-chaves: Hanseníase. Indicadores de eliminação da hanseníase. Taxa de detecção. Prevalência. Percentual de pacientes multibacilares.

The current strategy for the control of leprosy in Brazil is based on early case detection and treatment of all cases with multidrug therapy (MDT). As suggested by WHO, controlling leprosy in this country is conducted at the municipal level in order to ensure that diagnostic and treatment services are equitably distributed, affordable and easily accessible. Since stigma is so important for leprosy patients, control activities are integrated into the general health-care services. Reporting on cases of leprosy remains a vital step in controlling and preventing the spread of disease. In Brazil,

1. Department of Environmental Medicine and Public Health, University of Padova, Italy. 2. Fondazione Frà Roggero Caccia Dominioni, Venezia, Italy. 3. Governmental Leprosy Service, Floriano, Piauí, Brazil.

Financial support: University of Padova (fondi ex-60\% 2007).

Address to: Prof. Mastrangelo Giuseppe. Department of Environmental Medicine and Public Health, University of Padova, Via Giustiniani 2, 35128 Padova, Italy.

Tel: +39-049-821-2543

e-mail: giuseppe.mastrangelo@unipd.it

Received in 12/01/2009

Accepted in 06/10/2009 health authorities are required to provide notification of cases of leprosy within a week; the agency receiving this report is the local health department. Information on the infected person is provided by the local leprosy service; it is mandated that cases should be reported on a special form. The collected data (69 variables) are then computerized and distributed/made available through a web site.

Leprosy Elimination Monitoring (LEM) programs, undertaken in 27 Brazilian states by the Pan American Health Organization/ World Health Organization (PAHO/WHO) and the Brazilian Ministry of Health, are independent and formal sources of information, which can be used to supplement information provided by the Brazilian routine system of data collection and management. The epidemiological profile of leprosy from 1998 to 2002 was estimated through the LEM for the State of Piauí, using data collected in a random sample of four Piauí towns: Teresina, Floriano, Piripiri, and Picos ${ }^{11}$.

In an endemic area of North-East Brazil (the town of Picos, State of Piauí), a nongovernmental organization (NGO) supported 
the activity against leprosy in connection with governmental health organizations and local agents. The time trend of leprosy elimination indicators over time (within Picos) and across space (Picos versus Piauí) were compared. The epidemiological trends were examined and their likely interpretation with regard to future leprosy control activities in the area discussed.

\section{MATERIAL AND METHODS}

In the leprosy service of Picos, a medical doctor attending once a week was primarily responsible for diagnosing and prescribing medications, while nurses, social workers and paramedical personnel performed other activities. In connection with the government health organizations and local agents, the NGO team screens the sick person and dispenses MDT, as well as running the information campaigns and raising awareness among the population to fight the stigma, one of the main issues in leprosy control.

The clinical records of the patients (1996 to 2005) in the archive of this service were examined. The number of documents was varied considerably from one patient to another, and in most documents some information was missing. Nonetheless, it was possible to reconstruct the clinical history of most patients, since documents were largely overlapping making missing documents redundant. The electronic database of leprosy cases notified from 2000 to June 2006 in the Local Health Authority of Picos was also accessed

Only patients residing in the town of Picos were included in this study, while those coming from the region of Picos were excluded, because population data for these communities were unknown. All patients included in this study declared that they had never previously been treated for leprosy.

The following indicators for measuring progress towards the elimination of leprosy ${ }^{10}$ were used:

1. case detection rate (CDR), i.e., the number of cases detected during the year, and never previously treated for leprosy, per 10,000 population;

2. registered point prevalence (RPP), i.e., the number of cases registered for anti-leprosy chemotherapy still receiving treatment on December 31 of the index year per 10,000 population. Patients who had completed a full course of fixed duration MDT, and patients who had not received treatment for more than 12 consecutive months were removed from RPP;

3. proportion of new cases in children under 15 years of age detected during the year per 10,000 population under 15 years of age (\%children);

4. proportion of new cases with grade 2 disability (\%grade2), i.e., the number of patients with grade 2 disability divided by the number of patients for whom disability status was recorded during the year;

5. proportion of multibacillary (\%MB) patients among new cases detected during the year. Definition of MB cases was based upon skin smear and bacilloscopy;
6. average time between date of recognition of the disease, based on interview of patients, and date of diagnosis (diagnostic delay).

The population data (broken down by age, sex and year) required to calculate the rates were obtained from a website ${ }^{2}$.

Study design and analysis of data. The above epidemiological indicators were examined in the town of Picos over ten years (1996 to 2005), while the findings of Picos were compared with those of Piauí for a time window of five years (1998 to 2002).

The results were plotted on diagrams displaying a particular indicator against the year of occurrence. Using a program implemented in Microsoft Excel, a polynomial function of third degree was fitted to the points in order to obtain the trend of a particular indicator over ten years of observation. This was undertaken for Picos but not for Piauí, because there were too few points.

For statistical analysis, various techniques of regression analysis were used. The outcome variables were: CDR and RPP (considered as count data and fitted on a Poisson regression model, reporting the incidence rate ratio, IRR, as measure of effect); \%grade2, \%children, and \%MB (considered as binary response and fitted on generalized linear models for the binomial family estimating risk difference, $\mathrm{RD}$, as measure of effect); and diagnostic delay (considered as continuous response and analyzed by robust regression model, computing the regression coefficient, $\mathrm{RC}$ ). Calendar year was the only explanatory variable in all of the above regression analyses. Expected cases of leprosy in Picos, based on the experience of disease in the State of Piauí, were obtained as a product of leprosy incidence in Piauí per the number of persons living in Picos in each year from 1998 to 2002. Observed (0) and expected (E) cases were summed up over the five years of observation and divided by each other; a $0 / E$ ratio $>1$ indicated a higher incidence in the city than in the state. The chi square $\left(\chi^{2}\right)$ test $\left(=(0-E)^{2} / E\right)$ with one degree of freedom was used for statistical significance.

No ethical approval was required for the study since it was mandated by Picos Local Health Authority. All personal records were handled according to national rules concerning confidentiality.

\section{RESULTS}

In Picos, there were 186 leprosy patients from 1996 to 1999 (40, 47, 55, and 44, respectively, in 1996, 1997, 1998, and 1999), and 369 from 2000 to $2005(68,41,76,59,60$, and 65, respectively, in 2000, 2001, 2002, 2003, 2004, and 2005).

Frame A of Figure 1 shows that the time trend of CDR was upward in Picos (IRR=1.038; $\mathrm{p}=0.010)$ and Piauí. In Picos, CDR was above 8 per 10,000 population in the last two years of observation, twice as high as the threshold of hyperendemicity ( 4 per 10,000) according to the Brazilian Department of Health'. With $0=284$ and $E=184$, the ratio was 1.54 and $X^{2}=54.38$ $(\mathrm{p}<0.001)$, indicating a greater CDR in Picos than in Piauí.

Frame B of Figure 1 shows a downward trend over time of RPP in Picos (IRR=0.926; $\mathrm{p}<0.001$ ); it should be noted that RPP in 1996 could not be reliably estimated in Picos and was discarded. In the last years of observation RPP was around 5 per 10,000 


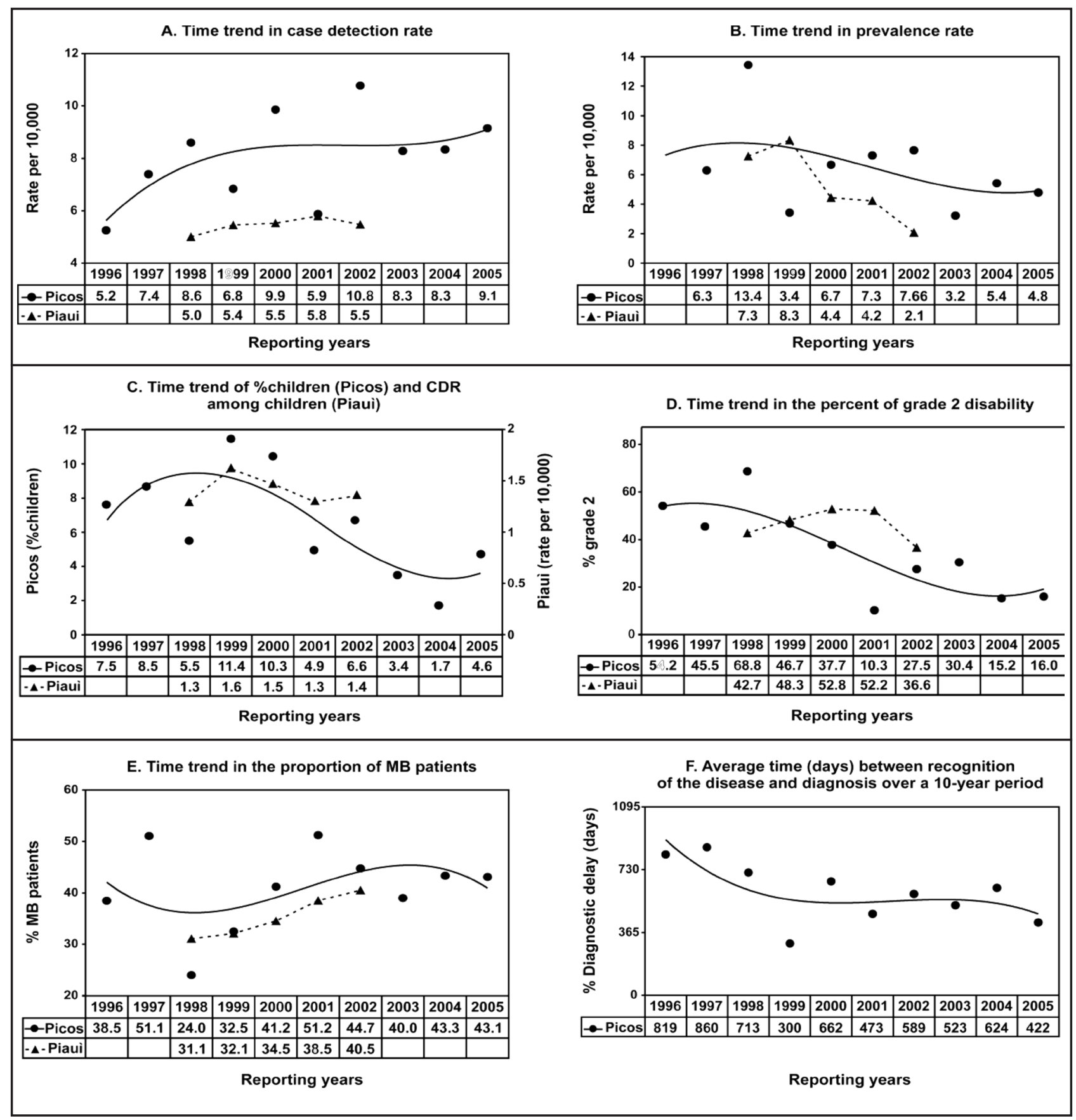

\section{FIGURE 1}

Time trend of six leprosy elimination indicators: case detection rate (CDR); registered point prevalence (RPP); proportion of new cases in children (\%children); proportion of new cases with grade 2 disability (\%grade2); proportion of multibacillary (\%MB); and diagnostic delay in Picos and Piauí. In each frame, y-axis reports an elimination indicator and $\mathrm{x}$-axis the reporting years. The lines represent the trend of a particular indicator over time.

people in Picos. With $\mathrm{O}=259$ and $\mathrm{E}=175, \mathrm{O} / \mathrm{E}=1.48$ and $\chi^{2}=40.37$ $(\mathrm{p}<0.001)$, suggesting a higher RPP in Picos than in Piauí.

Frame $\mathrm{C}$ of Figure 1 shows that there was a borderline significant reduction in \%children over time $(\mathrm{RD}=-0.007$; $\mathrm{p}=0.053)$ in Picos. The proportion was around $4 \%$ in the two last years of observation. In Piauí, only case detection rate in children under 15 years of age (per 10,000) was available, outlining a steady trend over time.

Frame D of Figure 1 shows that the proportion of patients with grade 2 disability was clearly decreasing in Picos $(\mathrm{RD}=-0.045$; $\mathrm{p}<0.001)$. Even in the last years of observation, approximately $20 \%$ of patients had a disability over grade 2 at diagnosis. In Piauí, this proportion increased from 1998 to 2001 then decreased in 2002.

Frame E of Figure 1 shows an upward time trend in the proportion of MB patients in Picos and Piauí. Using binomial regression analysis, however, no statistical difference over time was observed in \%MB in Picos $(\mathrm{RD}=0.008 ; \mathrm{p}=0.295)$.

Frame F of Figure 1 shows a descending trend in diagnostic delay in Picos, from 819 days (roughly 2 years) in 1996 to 422 (roughly 1 year) in 2005. Using robust regression analysis, $\mathrm{RC}$ was -44.3 and $\mathrm{p}>0.001$. No information regarding this indicator was available for Piauí. 


\section{DISCUSSION}

In Picos, the prevalence was still higher than one case per 10,000 of the population, the threshold under which leprosy can no longer be considered a public health problem, according to the World Health Assembly ${ }^{13}$. In the case of leprosy, 'prevalence' refers to the number of cases registered for chemotherapy. Prevalence rates of patients registered for treatment are not useful in assessing the current leprosy situation in an endemic area, since they are influenced by several factors: shorter periods of treatment duration; case detection methods; and updating of the registers ${ }^{12}$.

The new case detection rate may be a better indicator. CDR from 1996 to 2005 increased in Picos. Possible explanations might be expanding endemicity or increased case detection activities, including improved geographical coverage of the control program and increased awareness among the population in endemic countries. According to van Brakel ${ }^{13}$, CDR should be interpreted in conjunction with other indicators: \%children, \%MB, and \%grade2.

The \% children provides an indication of the levels of transmission occurring in the recent past. Several studies have shown that when the incidence of leprosy decreases, age of onset (or detection) will tend to increase ${ }^{458}$. The \%children will therefore decrease and, once transmission is stopped completely, will eventually approach zero. This is well illustrated by the ALERT leprosy control area in Ethiopia ${ }^{1}$ and the example of Taiwan ${ }^{7}$. Since \%children was decreasing (borderline statistical significance), the most credible interpretation of CDR increase in Picos is improved detection activities.

It has been shown that \% $\mathrm{MB}$ increases in countries where leprosy was dying out ${ }^{46}$. This is because, on average, MB cases have longer incubation periods and therefore will continue to appear as new cases, even after transmission decreases or is stopped completely. If MB proportion is steady, CDR is considered to reflect the underlying incidence rate. In Picos no statistical difference was observed over time in \%MB, thus CDR increase could signify expanding endemicity. The proportion of MB in 1997 is an influential point affecting the line of tendency to a great extent. If it is removed, the whole trend tends to increase: the risk difference of $\mathrm{MB}$ proportion over time becomes 0.015 and $\mathrm{p}=0.064$, close to the threshold of statistical significance $(0.05)$. Moreover, it should be highlighted that the definition of 'MB' has changed several times in recent years and these changes make this indicator difficult to interpret.

The \%grade2 highlights a key problem in leprosy, namely disability due to untreated nerve damage. Visible impairments show a longer delay in diagnosis on average than those without impairment. In Picos, the highly significant $(<0.001)$ decrease in \%grade2 paralleled the remarkable reduction $(\mathrm{p}<0.001)$ in diagnostic delay indicating that 'grade 2 proportion' is a proxy indicator for delay in diagnosis ${ }^{3}$. The reduction in \%grade 2 among cases detected in Picos suggests that most of these new cases were incident cases with a relatively short delay in diagnosis. This might also signify that the hidden cases are decreasing, suggesting that CDR increase reflects intensified case detection, rather than disease spread.

The indicators of leprosy elimination showed a more favorable time trend in Picos than in the whole of Piauí (frames A to E).
Interestingly, the encouraging findings reported above occurred mostly in the second part of the observation period, when the reporting sources were doubled. The differences could be even higher, since in the LEM programs, Picos was one of the four towns included in the sample used to estimate the epidemiological profile of leprosy in Piauí. These improvements encouraged the NGO that has supported the program against leprosy in Picos to extend the coverage of leprosy prevention/treatment to the cities of Floriano and Oeiras in the State of Piauí.

\section{ACKNOWLEDGEMENTS}

The authors would like to thank Dr Patricia Albuquerque Martins Rodriguez (Municipal coordinator of Hanseniase, Picos, Piauí) who gave permission to examine the archives of the leprosy service in Picos. The authors are also grateful to His Excellency Frà Roggero Caccia Dominioni, Adeládio de Araújo Rocha, and Claudio Maria Marciano di Scala for their help, to Daisy Alice Dunger for editing the manuscript and to the University of Padova for funding the project.

\section{REFERENCES}

1. Groenen G. Trends in prevalence and case finding in the ALERT leprosy control programme, 1979-1999. Leprosy Review 73:29-40, 2002.

2. Instituto Brazileiro de Geografia e Statistica. Accessed on February 2007 at: http://tabnet.datasus.gov.br/cgi/ibge/popmap.htm

3. Irgens LM. Leprosy in Norway. An epidemiological study based on a national patient registry. Leprosy Review 51 (Suppl 1): 1-130, 1980.

4. Irgens LM. Epidemiological aspects and implications of the disappearance of leprosy from Norway; some factors contributing to the decline. Leprosy Review 52 (Suppl 1): 147-165, 1981.

5. Irgens LM, Skjaerven R. Secular trends in age at onset, sex ratio, and type index in leprosy observed during declining incidence rates. American Journal of Epidemiology 122: 695-705, 1985.

6. Irgens LM, Melo CF, Lechat MF. Leprosy in Portugal 1946-80: epidemiologic patterns observed during declining incidence rates. Leprosy Review 61:32-49, 1990

7. Lue HC, Chen JC, Chao JY, Hsiao D, Chou P, Wang LS. Epidemiology of leprosy in Taiwan; its pattern in children. International Journal of Leprosy and Other Mycobacterial Diseases 68:57-62, 2000.

8. Meima A, Gupte MD, van Oortmarssen GJ, Habbema JD. Trends in leprosy case detection rates. International Journal of Leprosy and Other Mycobacterial Diseases 65: 305-319, 1997

9. Ministério da Saúde do Brasil e Organização Pan-Americana da Saúde. Autoinstrução em análise de situações da endemia de Hanseníase. Accessed on February 2007 at: http://portal.saude.gov.br/portal/arquivos/pdf/auto_instrucao.pdf

10. Organización Pan-Americana de la Salud. Leprosy Elimination Monitoring, Guidelines for Monitors, 2000. Accessed on February 2007 at: http://www.who. int/lep/monitor/guidelines/en/index.html

11. Organización Pan-Americana de la Salud e Organización Mundial de la Salud. Piauí, Monitoramento da Eliminação da Hanseníase, 20 a 21 Julho de 2003. Accessed on February 2007 at: http://amro.who.int/Portuguese/AD/DPC/CD/leplem-2003-PI.pdf

12. Van Brakel WH, Lever P, Feenstra P. Monitoring the size of the leprosy problem: which epidemiological indicators should we use? Indian Journal Public Health 48:5-16, 2004.

13. World Health Assembly. Leprosy Resolution WHA 44.9, 44th World Health Assembly, 13 May 1991. 